\title{
Demographic characteristics and AMH levels in rural and urban women participating in an IVF programme
}

\author{
Michał Kunicki ${ }^{1,4}$, Krzysztof Łukaszuk ${ }^{1,2,3,4}$, Joanna Liss ${ }^{1,3}$, Grzegorz Jakiel ${ }^{1,5}$, Patrycja Skowrońska ${ }^{2}$ \\ 1 INVICTA Fertility and Reproductive Center, Warsaw, Poland \\ ${ }^{2}$ Department of Obstetrics and Gynecological Nursing, Faculty of Health Sciences, Medical University of Gdansk, Poland \\ ${ }_{3}^{3}$ INVICTA Fertility and Reproductive Center, Gdańsk, Poland \\ ${ }^{4}$ Department of Gynecological Endocrinology, Medical University of Warsaw, Poland \\ ${ }^{5}$ Department of Obstetrics and Gynaecology, Medical Center of Postgraduate Education, Warsaw, Poland
}

Kunicki M, Łukaszuk K, Liss J, Jakiel G, Skowrońska P. Demographic characteristics and AMH levels in rural and urban women participating in an IVF programme. Ann Agric Environ Med. 2018; 25(1): 120-123. doi: 10.26444/aaem/78944

\begin{abstract}
I Abstract
Objective. The primary aim of this preliminary study was to compare the IVF results of couples living in rural and urban areas. Additionally, the ovarian reserve parameters, such as AMH concentrations, were compared for the same groups.

Materials and method. The database of 1,265 women undergoing in vitro fertilization at the Invicta Fertility Center between May 2011-July 2012 were retrospectively analyzed. Women undergoing their first assisted reproductive technology cycle with ICSI, stimulated according to the long protocol, and whose AMH levels were measured using the same DSL kit, were selected. Ultimately, 651 women were included in the study. All participants were categorized based on the area where they live: rural areas, small towns $(<100,000$ inhabitants) and large cities $(>100,000)$

Results. The mean age of the patients living in large cities was significantly higher in comparison to those from rural areas and small towns. A significantly higher pregnancy body mass index (BMI) was found in women from rural areas in comparison to the women living in small and large towns. Serum AMH and inhibin B concentrations, number of ampules of gonadotropins, and antral follicle count (AFC), did not differ significantly among the groups. The study showed no significant differences among the groups in terms of clinical pregnancy rate, both per started cycle and per embryo transfer. Conclusions. No significant differences were found in IVF outcomes among the groups inhabiting rural areas, small and large cities.
\end{abstract}

I Key words

infertility, assisted reproductive technique, in vitro fertilization, anti mullerian hormone

\section{INTRODUCTION}

A variety of factors may affect the success rate of IVF treatment, most of which have been widely discussed in published literature. The most important factors are maternal age and Antimüllerian hormone (AMH) level $[1,2]$. The number and quality of the embryos available for transfer also play an essential role $[1,3,4]$. Different models predicting IVF success rate have been proposed, taking into account clinical and embryological data [5-7]. Additionally, various physical, occupational, behavioural and socio-economic factors affecting human fertility in men and women may also influence success of the IVF treatment [8-13]. Obesity and smoking are thought to be some of the most critical among these factors [4-16]. It has also been established that some drugs, heavy metals and solvents, may affect fertility [17-19]. However, there is relatively little data regarding IVF success depending on the type of area inhabited by the patient [20-23]. Thus, the primary aim of this preliminary study was to compare the IVF results among couples living in rural and urban areas. Additionally, the ovarian reserve parameters, such as AMH concentrations among the above mentioned groups, were compared.

Address for correspondence: Michał Kunicki, INVICTA Fertility and Reproductive Center, Warszawa, Poland

E-mail: michal.kunicki@invicta.pl

Received: 10.11.2015; accepted: 16.05.2016; first published: 23.10.2017

\section{MATERIALS AND METHOD}

The database of 1,265 women undergoing in vitro fertilization at the Invicta Fertility Center between May 2011 - July 2012 were retrospectively analyzed. The inclusion criteria were as follows:

a) women who chose the ICSI fertilization procedure;

b) women undergoing their first IVF treatment;

c) women whose AMH measurements were performed with the same DSL kit;

d)only those who had stimulation according to the long protocol.

Exclusion criteria included women who:

a) had previously undergone IVF procedure;

b) had participated in an oocyte/sperm donor programme;

c) had preimplantation genetic screening (PGS) or preimplantation genetic diagnosis (PGD) performed.

Ultimately, 651 women were included into the study.

Women were categorized according to their inhabitation area based on the following criteria [24]:

1. rural areas;

2. small towns ( $<100,000$ inhabitants);

3. large cities ( $>100,000$ inhabitants). 
The study protocol was approved by the institutional review board of the Medical University in Gdańsk, Poland (KB 16/14).

Statistical analysis was performed using Statistica 10.0 software. The normality of distribution of data was tested using Shapiro-Wilk test. Categorical data were presented as means (+/-standard deviation) or medians (25-75 quartile), when appropriate. Comparison between categories was made using ANOVA or Kruskal-Wallis test. Additionally, multiple comparison post-hoc test was applied when necessary. Chi square test with Yates correction was applied to present differences in nominal data among groups. A value of $\mathrm{p}<0.05$ was considered statistically significant.

\section{RESULTS}

The baseline characteristics of the study population are shown in Table 1.

The mean age of the patients in the large cities group was significantly higher in comparison to the other two groups. There were no significant age differences between women inhabiting rural areas and small towns. The youngest woman included in the study lived in a town with $<100,000$ inhabitants (small town) and was 22 years old, and the oldest lived in a city with $>100,000$ inhabitants (large city) and was 51 years old. The mean duration of infertility was 4 years and did not differ significantly among the groups.

The lowest body mass index (BMI) was recorded in the group of women living in large cities. The highest BMI was in the rural area group. The mean BMI differed significantly among groups.

No significant differences were found with respect to serum $\mathrm{AMH}$ and inhibin $\mathrm{B}$ concentrations, number of ampules of gonadotropins, and antral follicle count (AFC).

The doses of follicle-stimulating hormone used for ovarian induction per cycle, the number of days of stimulation, the number of cumulus complexes, metaphase II oocytes, fertilization rate, and number of transferred embryos, also showed no statistically significant differences. Additionally, no significant differences were found between groups with respect to clinical pregnancy rate both per started cycle as well as per embryotransfer. The highest clinical pregnancy rate was found in the group of women living in large cities. However, the same group had also the highest miscarriage rate. There were no significant differences in respect to basal hormone concentrations between groups (Tab. 2). No significant differences were found among all three groups with respect to the causes of infertility (Tab. 3). Male factor was the most common cause of infertility across all three groups.

Table 1. Baseline characteristics of study population, treatment variables and IVF outcome

\begin{tabular}{|c|c|c|c|c|}
\hline & Rural ( $n=155)$ & Urban $<100000(n=206)$ & Urban $>100.000(n=285)$ & $\mathrm{p}$ value \\
\hline Age $(y)$ & $33(31-37)$ & $34(31-36)$ & $35(32-37)$ & 0.02 \\
\hline Total gonadotropin dose (ampoules 75 IU) & $21(18-26)$ & $20(17.75-25)$ & $21(18-28)$ & 0.23 \\
\hline $\mathrm{AMH} \mathrm{ng} / \mathrm{ml}$ & $2(1-3.7)$ & $2.1(1.2-3.7)$ & $2.1(1.1-3.5)$ & 0.96 \\
\hline INHIBIN B pg/ml & $65.3(37.65-94.97)$ & $74.35(47.3-102.3)$ & $63.9(26.7-91.17)$ & 0.05 \\
\hline AFC & $10(7-16)$ & $11(8-15)$ & $11(7-16)$ & 0.79 \\
\hline No. of cumulus & $10(6.75-15)$ & $11(7-16)$ & $10(7-15)$ & 0.53 \\
\hline No. of mature oocytes & $6(4-9)$ & $7(4-10)$ & $6(4-9)$ & 0.56 \\
\hline Fertilzation rate (\%) & $62.96 \%$ & $63.16 \%$ & $66.05 \%$ & 0.41 \\
\hline No. of embryos transferred & $2(1-2)$ & $2(1-2)$ & $2(1-2)$ & 0.32 \\
\hline 0 & 6 & 5 & 8 & \\
\hline 1 & 34 & 50 & 83 & \\
\hline 2 & 110 & 142 & 185 & \\
\hline Biochemical pregnancy rate $(\%)$ & $18.70 \%$ & $19.41 \%$ & $18.49 \%$ & 0.87 \\
\hline Clinical pregnancy rate (\%) per cycle started & $38.06 \%$ & $39.80 \%$ & $37.54 \%$ & 0.92 \\
\hline Clinical pregnancy rate (\%) per embryo transfer & 39.59 & 41.62 & 39.62 & 0.94 \\
\hline Miscarriage rate (\%) & $5.80 \%(9 / 155)$ & $5.82 \%(12 / 206)$ & $3.85 \%(11 / 270)$ & 0.67 \\
\hline BMI $\left(\mathrm{kg} / \mathrm{m}^{2}\right)$ & $22.30(20.54-26.8)$ & $21.56(19.84-23.83)$ & $21.37(19.67-23.43)$ & 0.02 \\
\hline Duration of infertility (years) & $4(3-7)$ & $4(2-6)$ & $4(2-6)$ & 0.06 \\
\hline Smoking & $18.91 \%$ & $15.21 \%$ & $13.72 \%$ & 0.71 \\
\hline
\end{tabular}

Table 2. Hormonal profile of participating women

\begin{tabular}{lcccc}
\hline & Rural areas & Small town & Large town & p value \\
\hline $\mathrm{LH}(\mathrm{IU} / \mathrm{L})$ & $6.1(4.7-10.2)$ & $5.9(4.72-9.7)$ & $6.7(4.62-10.1)$ & 0.98 \\
\hline $\mathrm{FSH}(\mathrm{IU} / \mathrm{L})$ & $6.7(2.3-18.1)$ & $6.1(3-42)$ & $6.5(0.9-41)$ & 0.55 \\
\hline $\mathrm{E} 2(\mathrm{pg} / \mathrm{ml})$ & & $1613.95( \pm 1173.08)$ & $2113( \pm 1470.6683)$ & 0.58 \\
\hline $\mathrm{T}(\mathrm{ng} / \mathrm{ml})$ & $1.12(0.3-2.7)$ & $1.1(0.7-3.3)$ & $1.1(0.5-4.1)$ & 0.76 \\
\hline PRL0' $(\mathrm{mU} / \mathrm{L})$ & $\begin{array}{c}264.4 \\
(167-1109)\end{array}$ & $\begin{array}{c}280 \\
(84-409)\end{array}$ & $\begin{array}{c}289.35 \\
(17.51-1146)\end{array}$ & 0.99 \\
\hline DHEAS $(\mathrm{ug} / \mathrm{dl})$ & $\begin{array}{c}235.4348 \\
( \pm 101.4234)\end{array}$ & $\begin{array}{c}253.89 \\
( \pm 95.00)\end{array}$ & $\begin{array}{c}220,9375 \\
( \pm 80.14)\end{array}$ & 0.44 \\
\hline SHBG $(\mathrm{ng} / \mathrm{ml})$ & $63.5(18-112)$ & $64(14-168)$ & $58(10-200)$ & 0.64
\end{tabular}

Table 3. Cause of infertility in women from rural and urban areas (\%)

\begin{tabular}{lcccc}
\hline & Rural areas & Small town & Large town & p value \\
\hline Tubal factor & 11.11 & 11.46 & 8.57 & 0.56 \\
Male factor & 36.50 & 38.21 & 31.90 & 0.35 \\
Endometriosis & 6.34 & 8.28 & 10.47 & 0.43 \\
Anovulation & 0.79 & 1.27 & 2.38 & 0.58 \\
Other & 7.14 & 8.28 & 10.95 & 0.47 \\
Unexplained & 31.74 & 27.38 & 30.95 & 0.66 \\
Mixed & 6.34 & 5.09 & 4.76 & 0.87 \\
\hline
\end{tabular}




\section{DISCUSSION}

It has been proved that the success of in vitro fertilization treatment is related to occupational, chemical and lifestyle factors [7-9]. It has also been shown that the infertility rate among couples living in polluted areas is higher in comparison to those living in unpolluted ones. There are studies presenting different statistics with regard to the incidents of infertility for different countries or regions [10]. Additionally it has been shown that access to assisted reproductive techniques (ART) varies in different countries $[25,26]$. In the opinion of the authors of this study, all those factors could also have a great impact on the number of couples from both rural and urban areas who participate in IVF treatment.

The current study included only women who had first IVF-ICSI treatment and had their AMH level measured using the same DSL kit. The vast majority of cycles were performed using the ICSI technique, and such cycles were included into the study. In order to make the obtained data more homogenous, women who had PGS/PGD and those who used donor eggs in their treatment were also excluded.

During the analyzed period, more women from urban than from rural areas were included into the study. The explanation is likely complex, as access to ART treatment depends on a variety of factors, such as increasing age at marriage, marital status, education, race, and especially income [27-30].

It can be speculated that the higher average income of women living in cities could have influenced the number of participants from large cities as IVF treatment was not covered in any way by public health insurance during the time period covered by this study. The findings obtained agree with previous research that showed that the vast majority of women dealing with infertility live in cities [31]. Another study showed that access to specialist laboratory tests and specialist medical care is limited in rural areas [32]. There is also a race differences in fertility service (due to financial, language and religious factors)[33]. All the women included in the presented study were Caucasian, thus the race factor seems not to have affected the results.

Woman's age is the main independent factor influencing the IVF success rate. Previous research has shown that the age of women when they first try to conceive is related to the type of area in which they live [13]. The highest median age of women included in this study was in group inhibiting large urban areas. This could be partially explained by the fact that women living in larger cities tend to postpone starting a family due to their career goals. The results obtained for the current study are in agreement with earlier research showing that women's education level could influence their procreation decisions, including the timing of their first attempts to conceive [32].

Despite the fact that there were significant differences in the ages of participants (women from cities were significantly older), no significant differences were found in miscarriage and clinical pregnancy rates.

The large cities group had a lower incidence of smoking (although not statistically significant) that could be explained by higher education and better access to healthcare. There are conflicting opinions with regard to smoking and its influence on IVF-ET results [34-37]. In the study by Weigert [35], patients who smoked showed a significantly lower embryo scores and produced fewer oocytes, with fewer of them being fertilized and transferred. The same results were obtained by Wdowiak et al. in rural and urban populations [34]. Opposite results were presented by Cinar et al. [35] who found no significant differences when male and/or female smoking status was analyzed for fertilization rates, transferred embryo qualities and clinical pregnancy rates.

In the current study, a significantly higher body mass index (BMI) was found in women from rural areas, compared to women living in small and large towns.

Similar to the issue of smoking, there are conflicting research resultss concerning BMI and IVF in published literature [39-42].

In the current study, it was found that the clinical pregnancy rate was similar between groups with the highest rate recorded in the group living in cities $>100000$. This finding is contrary to those presented by Milewski et al. [20] who found that the higher pregnancy rate was recorded for women from rural areas. Different results were presented by Carpenter et al. [35], who showed that the incidence of infertility was greater in couples residing in urban areas, compared to populations who resided in relatively unpolluted areas.

In the current study group, primary infertility was more frequent than secondary infertility. This finding is in agreement with those presented by Sołtysiak [31], whose study had $67 \%$ of women with primary infertility.

Analysis of fertility causes revealed that the male factor was the most frequently occurring cause in all three groups. No significant differences were found among groups, although in both small towns and rural areas there was a slightly higher percentage of couples affected by this factor. According to some research, the prevalence of the male factor as a cause of infertility has been increasing, and its higher occurrence in towns could be related to higher exposure to toxins $[22,30]$. However, other published reports are to the contrary. A study of agricultural workers in Austria seeking IVF treatment, found a higher prevalence of male factor infertility, compared to non-agro controls [43].

The second most common factor in all groups was idiopathic infertility. Tubal factor was the most common cause of infertility for women living in towns $(<100,000$ inhabitants), although with no significant differences among the three populations were found. The presented findings differ from those presented by Milewski where the tubal factor was more frequent in women from rural areas [20]. The authors explained that this was due to worse access to medical care and lower awareness of sexually transmitted diseases.

The second goal of this study was to compare AMH levels between groups living in different areas. To-date, the authors have not found a similar comparison of AMH concentrations among women living in different types of areas. $\mathrm{AMH}$ is an established marker of ovarian reserve, and is currently considered, as the best predictor of IVF success $[37,44,45]$. The current goal included only women who had AMH measurement made by the same DSL kit. No significant differences in mean $\mathrm{AMH}$ levels were found among the three groups.

The main limitation of this study is that it was not possible to take into account the migrations of populations, a factor that could have influenced the results. Moreover, data such as marital status, alcohol and caffeine use and income, which could have allowed for some additional interesting analysis, were also not included [30]. The strength of the study is the homogeneity of the investigated group.

In conclusion, besides age, no differences were found in IVF results between study groups living in different areas. It seems that inhabitation areas have limited impact on IVF success rates. This study should be regarded as preliminary, and further studies are needed in this field. 


\section{REFERENCES}

1. Broekmans FJ, Kwee J, Hendriks DJ, Mol BW, Lambalk CB. A systematic review of tests predicting ovarian reserve and IVF outcome. Hum Reprod Update. 2006; 12(6): 685-718.

2. La Marca A, Nelson SM, Sighinolfi G, Manno M, Baraldi E, Roli L, et al. Anti-Müllerian hormone-based prediction model for a live birth in assisted reproduction. Reprod Biomed Online. 2011; 22(4): 341-9.

3. Cai QF, Wan F, Huang R, Zhang HW. Factors predicting the cumulative outcome of IVF/ICSI treatment: a multivariable analysis of 2450 patients. Hum Reprod. 2011; 26(9): 2532-40.

4. Hourvitz A, Lerner-Geva L, Elizur SE, Baum M, Levron J, David $B$, et al. Role of embryo quality in predicting early pregnancy loss following assisted reproductive technology. Reprod Biomed Online. 2006; 13(4): 504-9.

5. Bancsi LFJMM, Broekmans FJM, Eijkemans MJC, de Jong FH, Habbema JDF, te Velde ER. Predictors of poor ovarian response in in vitro fertilization: a prospective study comparing basal markers of ovarian reserve. Fertil Steril. 2002; 77(2): 328-36.

6. Verberg MFG, Eijkemans MJC, Macklon NS, Heijnen EMEW, Fauser BCJM, Broekmans FJ. Predictors of ongoing pregnancy after singleembryo transfer following mild ovarian stimulation for IVF. Fertil Steril. 2008; 89(5): 1159-65.

7. Te Velde ER, Nieboer D, Lintsen AM, Braat DDM, Eijkemans MJC Habbema JDF, et al. Comparison of two models predicting IVF success; the effect of time trends on model performance. Hum Reprod. 2014; 29(1): 57-64.

8. Younglai EV, Holloway AC, Foster WG. Environmental and occupational factors affecting fertility and IVF success. Hum Reprod Update. 2005; 11(1): 43-57.

9. ESHRE Task Force on Ethics and Law, including, Dondorp W, de Wert G, Pennings G, Shenfield F, Devroey P, et al. Lifestyle-related factors and access to medically assisted reproduction. Hum Reprod Oxf Engl. 2010; 25(3): 578-83

10. Boivin J, Bunting L, Collins JA, Nygren KG. International estimates of infertility prevalence and treatment-seeking: potential need and demand for infertility medical care. Hum Reprod Oxf Engl. 2007; 22(6): 1506-12.

11. Jain T, Hornstein MD. Disparities in access to infertility services in a state with mandated insurance coverage. Fertil Steril. 2005; 84(1): 221-3.

12. Kessler LM, Craig BM, Plosker SM, Reed DR, Quinn GP. Infertility evaluation and treatment among women in the United States. Fertil Steril. 2013; 100(4): 1025-1032.e2.

13. Homan GF, Davies M, Norman R. The impact of lifestyle factors on reproductive performance in the general population and those undergoing infertility treatment: a review. Hum Reprod Update. 2007; 13(3): 209-23.

14. Rittenberg V, Seshadri S, Sunkara SK, Sobaleva S, Oteng-Ntim E, ElToukhy T. Effect of body mass index on IVF treatment outcome: an updated systematic review and meta-analysis. Reprod Biomed Online. 2011; 23(4): 421-39.

15. Klonoff-Cohen H, Natarajan L, Marrs R, Yee B. Effects of female and male smoking on success rates of IVF and gamete intra-Fallopian transfer. Hum Reprod Oxf Engl. 2001 Jul;16(7):1382-90.

16. Florack EI, Zielhuis GA, Rolland R. Cigarette smoking, alcohol consumption, and caffeine intake and fecundability. Prev Med. 1994 Mar;23(2):175-80

17. Kim D, Bloom MS, Parsons PJ, Fitzgerald EF, Bell EM, Steuerwald AJ, et al. A pilot study of seafood consumption and exposure to mercury, lead, cadmium and arsenic among infertile couples undergoing in vitro fertilization (IVF). Environ Toxicol Pharmacol. 2013; 36(1):30-4

18. Snijder CA, te Velde E, Roeleveld N, Burdorf A. Occupational exposure to chemical substances and time to pregnancy: a systematic review. Hum Reprod Update. 2012; 18(3): 284-300.

19. Figà-Talamanca I, Traina ME, Urbani E. Occupational exposures to metals, solvents and pesticides: recent evidence on male reproductive effects and biological markers. Occup Med Oxf Engl. 2001; 51(3): 174-88.

20. Milewski R, Milewska AJ, Czerniecki J, Leśniewska M, Wołczyński S. [Analysis of the demographic profile of patients treated for infertility using assisted reproductive techniques in 2005-2010]. Ginekol Pol. 2013; 84(7): 609-14.

21. Mac Dougall K, Beyene Y, Nachtigall RD. Age shock: misperceptions of the impact of age on fertility before and after IVF in women who conceived after age 40. Hum Reprod Oxf Engl. 2013; 28(2): 350-6.
22. Carpenter DO, Shen Y, Nguyen T, Le L, Lininger LL. Incidence of endocrine disease among residents of New York areas of concern. Environ Health Perspect. 2001;109 Suppl 6: 845-51.

23. Juul S, Karmaus W, Olsen J. Regional differences in waiting time to pregnancy: pregnancy-based surveys from Denmark, France, Germany, Italy and Sweden. The European Infertility and Subfecundity Study Group. Hum Reprod Oxf Engl. 1999; 14(5): 1250-4.

24. Runge A. Medium-sized towns in the context of size structural changes of towns in Poland. Medium sized towns of Central-Eastern Europe in the period ofeconomic system transformation and social changes, National Academy of Public Administrationat the President of Ukraine, Kharkiv Regional Institute of Public Administration. 2011th ed. Kharkiv: Publishing House "ADNDU”; p. 66-87.

25. Huang JYJ, Rosenwaks Z. In vitro fertilisation treatment and factors affecting success. Best Pract Res Clin Obstet Gynaecol. 2012; 26(6): 777-88.

26. Farland LV, Missmer SA, Rich-Edwards J, Chavarro JE, Barbieri RL, Grodstein F. Use of fertility treatment modalities in a large United States cohort of professional women. Fertil Steril. 2014; 101(6): 1705-10.

27. Jain T, Harlow BL, Hornstein MD. Insurance coverage and outcomes of in vitro fertilization. N Engl J Med. 2002; 347(9): 661-6.

28. Bhattacharya S, Porter M, Amalraj E, Templeton A, Hamilton M, Lee AJ, et al. The epidemiology of infertility in the North East of Scotland. Hum Reprod Oxf Engl. 2009; 24(12): 3096-107.

29. Łepecka-Klusek C, Wdowiak A, Pilewska-Kozak AB, Syty K, Jakiel $\mathrm{G}$. The role of age, environmental and occupational factors on semen density. Ann Agric Environ Med AAEM. 2011; 18(2): 437-40.

30. Klonoff-Cohen H. Female and male lifestyle habits and IVF: what is known and unknown. Hum Reprod Update. 2005; 11(2): 179-203.

31. Sołtysiak E. [The influence of socioeconomic factors on female fertility]. Ginekol Pol. 2005; 76(12): 986-90.

32. Mascarenhas MN, Flaxman SR, Boerma T, Vanderpoel S, Stevens GA. National, Regional, and Global Trends in Infertility Prevalence Since 1990: A Systematic Analysis of 277 Health Surveys. Low N, editor. PLoS Med. 2012; 9(12):e1001356.

33. Jain T. Socioeconomic and racial disparities among infertility patients seeking care. Fertil Steril. 2006; 85(4): 876-81.

34. Wdowiak A, Lewicka M, Plewka K, et al. Nicotinism and quality of embryos obtained in in-vitro fertilization programmes. Ann Agric Environ Med. 2013; 20(1): 82-85.

35. Cinar O, Dilbaz S, Terzioglu F, Karahalil B, Yücel C, Turk R, et al. Does cigarette smoking really have detrimental effects on outcomes of IVF? Eur J Obstet Gynecol Reprod Biol. 2014;174:106-10.

36. Weigert M, Hofstetter G, Kaipl D, Gottlich H, Krischker U, Bichler K, et al. The effect of smoking on oocyte quality and hormonal parameters of patients undergoing in vitro fertilization-embryo transfer. J Assist Reprod Genet. 1999; 16(6): 287-93.

37. Fréour T, Dessolle L, Lammers J, Lattes S, Barrière P. Comparison of embryo morphokinetics after in vitro fertilization-intracytoplasmic sperm injection in smoking and nonsmoking women. Fertil Steril. 2013; 99(7): 1944-50.

38. Sterzik K, Strehler E, De Santo M, Trumpp N, Abt M, Rosenbusch B, et al. Influence of smoking on fertility in women attending an in vitro fertilization program. Fertil Steril. 1996; 65(4): 810-4.

39. Bellver J, Ayllón Y, Ferrando M, Melo M, Goyri E, Pellicer A, et al. Female obesity impairs in vitro fertilization outcome without affecting embryo quality. Fertil Steril. 2010; 93(2): 447-54.

40. Jungheim ES, Schon SB, Schulte MB, DeUgarte DA, Fowler SA, Tuuli MG. IVF outcomes in obese donor oocyte recipients: a systematic review and meta-analysis. Hum Reprod Oxf Engl. 2013; 28(10): 2720-7.

41. Caillon H, Fréour T, Bach-Ngohou K, Colombel A, Denis MG, Barrière $P$, et al. Effects of female increased body mass index on in vitro fertilization cycles outcome. Obes Res Clin Pract. 2015

42. Schliep KC, Mumford SL, Ahrens KA, Hotaling JM, Carrell DT, Link $\mathrm{M}$, et al. Effect of male and female body mass index on pregnancy and live birth success after in vitro fertilization. Fertil Steril. 2015; 103(2): 388-95.

43. Strohmer H, Boldizsar A, Plöckinger B, Feldner-Busztin M, Feichtinger W. Agricultural work and male infertility. Am J Ind Med. 1993; 24(5): 587-92.

44. Dewailly D, Andersen CY, Balen A, Broekmans F, Dilaver N, Fanchin $\mathrm{R}$, et al. The physiology and clinical utility of anti-Mullerian hormone in women. Hum Reprod Update. 2014; 20(3): 370-85.

45. Iliodromiti S, Kelsey TW, Wu O, Anderson RA, Nelson SM. The predictive accuracy of anti-Müllerian hormone for live birth after assisted conception: a systematic review and meta-analysis of the literature. Hum Reprod Update. 2014; 20(4): 560-70. 